\title{
Modeling community integration in workers with delayed recovery from mild traumatic brain injury
}

Tatyana Mollayeva ${ }^{1,2^{*}}$, Colin M. Shapiro ${ }^{3,4}$, Shirin Mollayeva ${ }^{5,6}$, J. David Cassidy ${ }^{7,8}$ and Angela Colantonio 2,9

\begin{abstract}
Background: Delayed recovery in persons after mild traumatic brain injury (mTBI) is poorly understood. Community integration $(\mathrm{Cl})$ is endorsed by persons with neurological disorders as an important outcome. We aimed to describe $\mathrm{Cl}$ and its associated factors in insured Ontario workers with delayed recovery following mTBI.

Methods: A cross-sectional study of insured workers in the chronic phase following mTBI was performed at a rehabilitation hospital in Ontario, Canada. Sociodemographic, occupational, injury-related, clinical, and claim-related data were collected from self-reports, medical assessments, and insurers' referral files. Community Integration Questionnaire $(\mathrm{ClQ})$ scores were compared using analysis of variance or Spearman's correlation tests. Stepwise multivariable linear regression models were used to evaluate the associations with $\mathrm{Cl}$.

Results: Ninety-four workers with mTBI (45.2 \pm 9.9 years old, $61.2 \%$ male) at 197 days post-injury (interquartile range, 139-416 days) were included. The CIQ total and subscale scores were similar to those reported in more severe TBI samples. The CIQ scores were moderately to strongly correlated with various sociodemographic, claim-related, and clinical variables. In the multivariable regression analysis, several covariates accounted for $36.4 \%$ of the CIQ variance in the final fully adjusted model.

Discussion: This study evaluated Cl in workers with $\mathrm{mTBI}$, and analyzed its associated variables. Analysis revealed insomnia, head or neck pain, being married or in a relationship, time since injury, and a diagnosis of possible/probable malingering were independently associated with limited $\mathrm{Cl}$.

Conclusions: Workers with delayed recovery from $\mathrm{mTBI}$ experience difficulty with $\mathrm{Cl}$. Insomnia is a particularly relevant covariate, explaining the greater part of its variance. To enhance participation, care should focus on clinical and non-clinical covariates.
\end{abstract}

Keywords: Insomnia, Traumatic brain injury, Concussion, Recovery, Community integration, Diagnostic modeling

\section{Background}

Traumatic brain injury (TBI) is a serious neurological disorder [1-3], with variable outcomes that include significant morbidity [4-7] and a decreased ability to function in society [5-9]. Moderate, severe, and penetrating TBIs are associated with the most adverse effects [9-14], although the effects of mild TBI (mTBI) have recently

\footnotetext{
* Correspondence: tatyana.mollayeva@utoronto.ca

'Graduate Department of Rehabilitation Science, Collaborative Program in Neuroscience, University of Toronto, Toronto, Canada

${ }^{2}$ Toronto Rehab-University Health Network, Ontario, Canada

Full list of author information is available at the end of the article
}

received increased attention, as approximately $75 \%$ of all TBIs are due to mild or concussive events [15-18]. Many persons with mTBI recover fully, usually within days or weeks $[18,19]$, although $15-23 \%$ of patients experience disabling symptoms that persist beyond 3 months [20, 21].

Many of these symptoms are not specific to TBI [22], and while the list is long, insomnia, the inability to sleep adequately at night given the opportunity [23], has been recognized as extremely important for explaining many of these symptoms in the general population, including 
cognitive disturbances, dizziness, fatigue, depression, and pain $[24,25]$.

When confronted with persistent symptoms long after the injury, most relevant parties (i.e., clinicians, insurers, and claim adjudicators) are not aware of their indicators [26]. Therefore, unnecessary clinical and diagnostic investigations may be ordered to assist the parties in their decision making. These investigations typically focus on variables that are derived from three predictive models for adverse mTBI outcomes. However, when the Transforming Research and Clinical Knowledge in TBI (TRACK-TBI) study was performed at three American medical centers to externally validate these models [27], researchers reported that two clinical models $[28,29]$ had minimal ability to discriminate between patients with favorable and non-favorable outcomes. The third model [30], featuring education, extracranial injury, and levels of post-concussion symptoms(i.e., depression, pain) as predictors of full return to work at 6 months post injury, could not be validated because of missing data. A focus on identifying more specific outcome measures was suggested for future research [27].

Recent initiatives have emphasized the importance of patients' perceptions when assessing neurological outcomes [31]. In this context, the most relevant outcomes include family comfort, economic and social participation [32], falling under community integration (CI) concept [33]. Therefore, post-mTBI CI may be useful for measuring injury outcomes [34].

Given the complexity of CI, we developed a model of CI for persons with TBI to investigate the following hypotheses among workers with delayed recovery from mTBI (Fig. 1): (1) CI would be poor; (2) insomnia would be negatively associated with CI; (3) previously reported clinical and claim-related variables [27-30] would be associated with CI; and (4) previously unexplored psychosocial variables (i.e., family relationship, personality traits) would be associated with CI.

\section{Methods}

This study's design was reviewed and approved by the Research Ethics Boards at the Toronto Rehab-University Health Network (UHN) and the University of Toronto. The findings were reported in compliance with the Transparent Reporting of a Multivariable Prediction Model for Individual Prognosis or Diagnosis (TRIPOD) guidelines [35].

\section{Procedure and participants}

Since 1998, the Neurology Service of the Toronto Rehab-UHN has provided exclusive expert diagnoses and treatment recommendations for Workplace Safety and Insurance Board (WSIB)-insured workers who have sustained a head trauma at work and have not returned to work within 3 months after the injury. The multidisciplinary team of specialists establishes a TBI diagnosis based on the initial loss of consciousness (LOC), Glasgow Coma Scale (GCS) score, post-traumatic amnesia (PTA), magnetic resonance imaging (MRI), and clinical assessment.

\section{Recruitment}

All participants were recruited between May 2012 and May 2014. Initial contact was made with prospective participants $(n=178)$ at orientation sessions, where they were informed of the ongoing study and were invited to participate. The final sample included 110 consenting

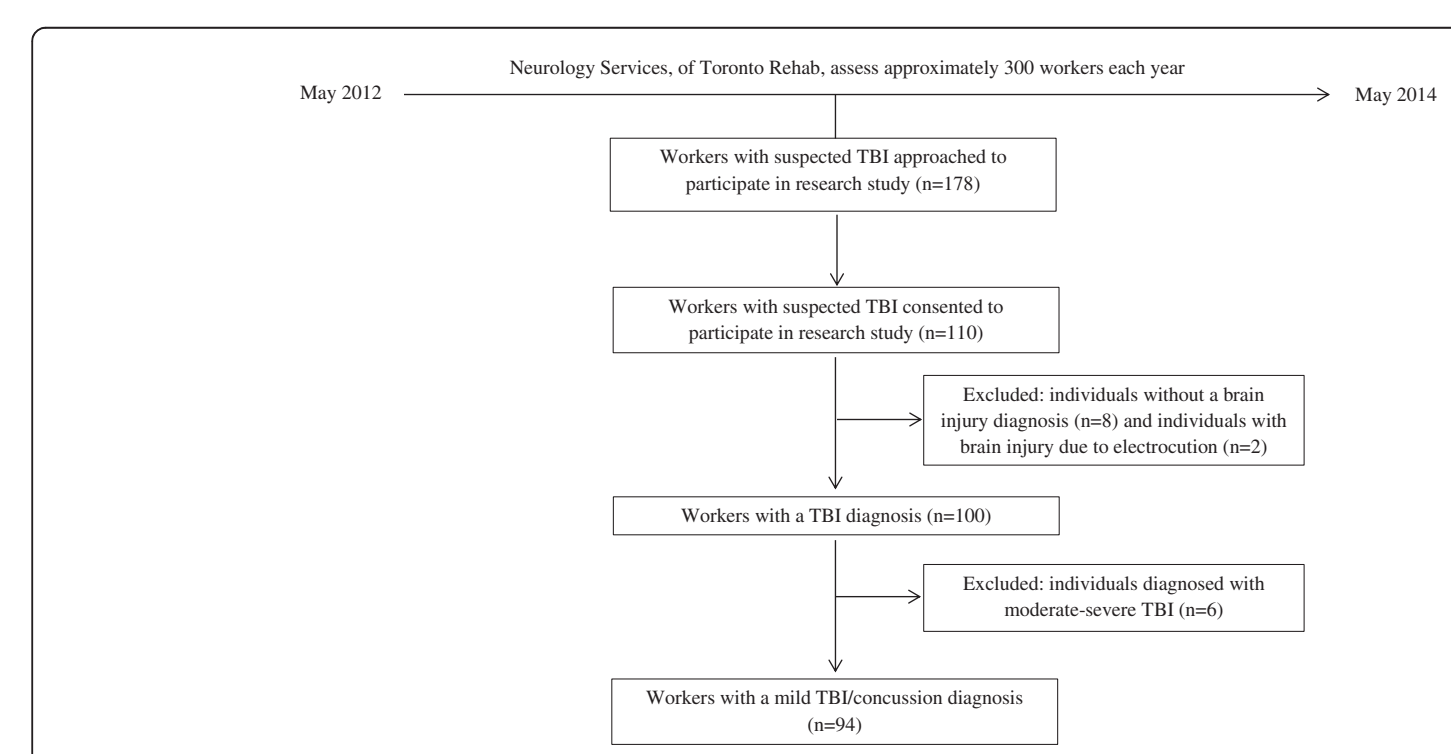

Fig. 1 Flow chart depicting process of selection of participating individuals' data for analysis. TB/ Traumatic brain injury 


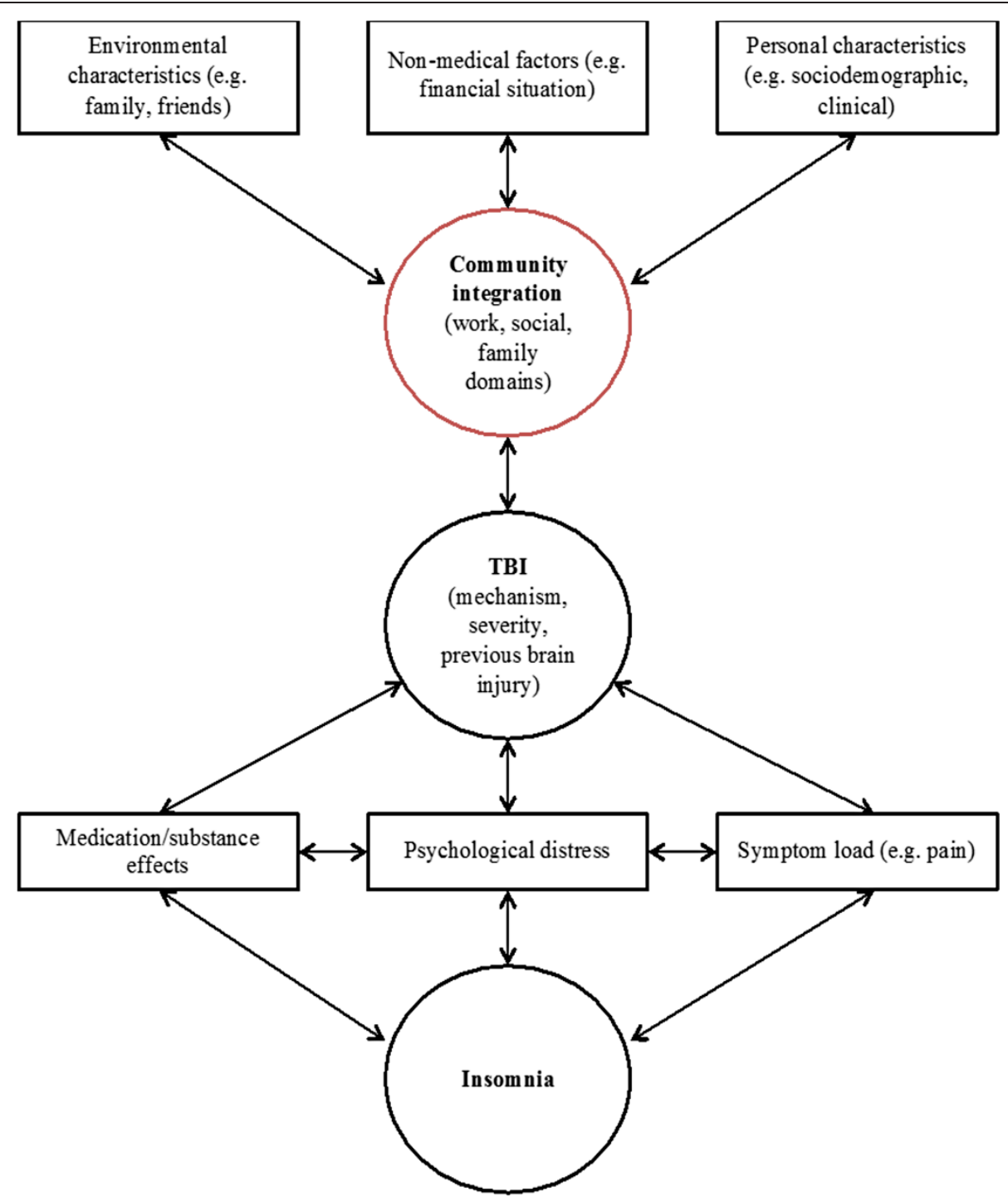

Fig. 2 Conceptual framework of the construct of community integration in traumatic brain injury (TBI). Format adapted from Fayer \& Hand [73]

(in writing) participants, including 94 participants who were later diagnosed with $\mathrm{mTBI} /$ concussion (Fig. 2).

To compare our sample to a consecutive sample of workers, and to indirectly assess our sample's representativeness, we performed a retrospective chart review of consecutive individuals $(n=294)$ who were referred for the same services and were assessed in the same clinic during 2003. No significant differences were observed in injury severity, sex, and age. Non-significant $(p>0.05)$ differences were observed in working status and marital status at the time of assessment. Our sample contained more people who were working part- or full-time at their assessment, and fewer people who were single, widowed, or divorced. To maintain sample homogeneity, our analyses only utilized data for participants who were diagnosed with mTBI $(n=94)$.

\section{Instruments and measures}

The clinical and diagnostic data included injury severity, presence of LOC, retrograde or anterograde PTA, and neuroimaging data. Clinical and claim-related variables were also collected from the participants' medical and WSIB files, and included previous disability claims, employeremployee relations, WSIB-worker relations, and cases of malingering (DSM-IV-TR Axis IV) [36]. Occupational variables were gathered from insurer files (i.e., Employers' Report of Injury/Illness Form 7), and included the workers' occupation and weekly salary at the time of injury. A detailed description of the instruments that were used is presented in Additional file 1: Table S1, and the studied variables are presented in Additional file 2: Table S2.

The Community Integration Questionnaire (CIQ) [37] total score was used to measure outcome. All self-reported 
data were collected at the same time as the outcome assessment. The diagnostic investigations and clinical assessments were performed within a short period, during which no intervening treatments were commenced.

\section{Statistical analysis}

SAS software (version 9.3, SAS Inc., Cary, NC) was used for all data analyses. Means and standard deviations or medians and ranges were used to describe continuous data, and frequency counts were used to describe categorical data. Continuous data were tested for normality before the analysis. Spearman's correlation coefficients $\left(r_{s}\right)$ were used to examine the associations between the CIQ total score and the continuous variables. A one-way analysis of variance was used to assess the associations between the CIQ total score and the categorical explanatory variables with two or more levels.

We built four regression models for the dependent variable (CIQ total score), grouping previously reported predictors and a priori hypotheses into: (1) sociodemographic, (2) clinical, (3) claim-related, and (4) injuryrelated models. To limit collinearity and ensure parsimonious models, Spearman's correlation coefficients were calculated for the clinically-relevant associations between covariates. The strongest correlations were observed between depression and insomnia $\left(\mathrm{r}_{\mathrm{s}}: 0.56\right)$, and between pain and insomnia $\left(r_{s}: 0.38\right)$. Stepwise eliminations were performed using $p$-values of $\geq 0.05$ as the limiting threshold. Sex and age were included in every model, regardless of any association. Data for two participants who were injured $>10$ years earlier were omitted. The final regression model was derived using variables that were significantly associated with CI in the four individual models. The final regression analysis indicated that the 92 participants provided sufficient power for this study, with approximately nine participants per independent variable $[38,39]$.

\section{Results}

Table 1 presents the characteristics of the 94 participants (58 men and 36 women) with a clinical diagnosis of mTBI. The mean age was $45.2 \pm 9.9$ years. Twenty-five workers $(27 \%)$ were single, widowed, or divorced, and 56 workers $(60 \%)$ had at least a post-secondary degree. Thirty-three workers (35\%) were in the middle or low weekly income categories at their injury.

Time since injury (TSI) distribution was greatly skewed (median, 197 days post-injury [interquartile range, 139-416 days]). The major mechanisms of injury were falls (19.1\%), being struck by $(19.1 \%)$ or against (17\%) an object, motor vehicle incidents (12.8\%), and being struck by a person (10.5\%). Among the 86 workers with available LOC and PTA data, $31 \%$ had experienced some degree of LOC and $24.7 \%$ had experienced PTA. Eighty-four participants underwent MRI, and none exhibited trauma-related brain changes.

Most participants (57\%) were receiving disability benefits at the time of assessment, and the rest were working full- or part-time. The most common pre-morbid occupational categories were skilled or factory workers and machine operators or assemblers (44\%); elementary occupations (35\%); managerial, professional, associate professional, or technician positions (14\%); and clerical support, service, or sales workers (7\%). Forty-five workers (47.9 \%) worked shifts at their injury; 38 (84 \%) worked rotating shifts; and 7 (16\%) worked night shifts.

Substantial proportions of the workers had one or more DSM-IV TR diagnoses (Table 1), including anxiety (45.5\%), mood (42.1\%), somatoform (29\%), and substance-related (14.8\%) disorders. Nine workers (10.2\%) were diagnosed with a sleep disorder, including 8 with a sleep-related breathing disorder. The most common post-morbid symptoms that affected functioning were head and neck pain (92.6\%), cognitive (71.3\%), mood- (66 \%), sleep- (63\%), and balance-related (47\%) disturbances, and bodily pain (34\%).

The CIQ was normally distributed and its internal consistency was appropriate(Cronbach's alpha, $\alpha=$ 0.70)(Figs. 3 and 4).

\section{Bivariate analyses}

Single, widowed, or divorced workers had significantly higher CIQ total scores $(p<0.001)$, compared to workers who were married or in relationships. Workers whose first language was English also had significantly higher CIQ scores $(p=0.006)$. In addition, participants who were employed as managers, professionals, technicians, or associate professionals had significantly higher CIQ scores $(p=0.014)$, compared to participants who worked in clerical support or service work, sales, and elementary occupations. Significant differences were observed in the CIQ scores for workers who did and did not report head and neck pain $(p=0.005)$. Workers with Axis IV-TR diagnoses of possible/probable malingering $(p<0.001)$, cluster B disorders $(p=0.004)$, cluster C disorders $(p=0.009)$, mood disorders $(p=0.049)$, and cognitive disorders $(p=0.004)$ had significantly lower CIQ scores. The CIQ scores were also negatively correlated with pain $(p<0.001)$, anxiety $(p=0.009)$, depression $(p<0.001)$, and insomnia $(p<0.001)$.

\section{Multivariable regression analyses}

Four preliminary multivariate linear regression analyses were performed to evaluate associations with CI. All models were age- and sex-adjusted (Fig. 5).

The final regression model included education, marital status, English as the first language, TSI, being struck by 
Table 1 Socio-demographic, injury-related, clinical, and claim-related characteristics of the study population

\begin{tabular}{|c|c|c|c|c|c|c|}
\hline Category & Variables & $n\left(\% N^{a}\right)$ & $\begin{array}{l}\text { Mean (SD)/median (Q3-Q1) } \\
\text { (continuous variables) }\end{array}$ & $\begin{array}{l}\text { CIQ score mean (SD) (binary/ } \\
\text { categorical variables) }\end{array}$ & $\begin{array}{l}\text { Rho } \\
\text { (continuous } \\
\text { variables) }\end{array}$ & $P$-value \\
\hline \multirow[t]{15}{*}{ Socio-demographic } & Sex & & & & & \\
\hline & Male & $58(62)$ & NA & $13.96(4.67)$ & NA & 0.086 \\
\hline & Female & $36(38)$ & & $15.56(6.01)$ & & \\
\hline & Age, years & $94(100)$ & $45.2(9.94)$ & NA & -0.092 & 0.377 \\
\hline & Marital status & & & & & \\
\hline & Married/common law & $69(73)$ & NA & $13.81(4.63)$ & NA & 0.018 \\
\hline & $\begin{array}{l}\text { Single/divorced/ } \\
\text { widowed }\end{array}$ & $25(27)$ & & $16.68(6.18)$ & & \\
\hline & English first language & & & & & \\
\hline & Yes & $77(82)$ & NA & $14.82(4.85)$ & NA & 0.079 \\
\hline & No & $17(18)$ & & $12.47(6.66)$ & & \\
\hline & Education & & & & & \\
\hline & $\leq$ High school & $34(36)$ & NA & $11.21(3.28)$ & NA & 0.006 \\
\hline & $\begin{array}{l}\text { High school-college, } \\
\text { prof. diploma }\end{array}$ & $32(34)$ & & $14.45(5.78)$ & & \\
\hline & University and higher & $24(27)$ & & $17.20(4.89)$ & & \\
\hline & Weekly income, \$CAD & $94(100)$ & $1056(510)$ & NA & 0.189 & 0.074 \\
\hline \multirow[t]{23}{*}{ Injury-related } & Time since injury, days & $94(100)$ & $197(416-139)$ & NA & -0.166 & 0.110 \\
\hline & Mechanism of injury & & & & & \\
\hline & $\begin{array}{l}\text { Struck by inanimate } \\
\text { object }\end{array}$ & & & & & \\
\hline & Yes & $18(19)$ & NA & $12.67(4.33)$ & NA & 0.084 \\
\hline & No & $76(81)$ & & $15.03(5.32)$ & & \\
\hline & Struck by another person & & & & & \\
\hline & Yes & $10(11)$ & & $17.10(4.89)$ & & 0.105 \\
\hline & No & $84(89)$ & & $14.27(5.19)$ & & \\
\hline & $\begin{array}{l}\text { Struck against object/ } \\
\text { structure }\end{array}$ & & & & & \\
\hline & Yes & $16(17)$ & & $16.62(4.81)$ & & 0.247 \\
\hline & No & $78(83)$ & & $14.38(5.23)$ & & \\
\hline & Fall & & & & & \\
\hline & Yes & $18(19)$ & & $13.61(5.09)$ & & 0.386 \\
\hline & No & $76(81)$ & & $14.80(5.25)$ & & \\
\hline & Loss of consciousness & $86(100)^{a}$ & & & & \\
\hline & Yes & $29(31)$ & NA & $14.17(6.14)$ & NA & 0.572 \\
\hline & No & $56(69)$ & & $14.86(4.78)$ & & \\
\hline & Post-traumatic amnesia & $86(100)^{a}$ & & & & \\
\hline & Yes & $21(25)$ & NA & $13.62(6.00)$ & NA & 0.235 \\
\hline & No & $65(75)$ & & $15.15(4.81)$ & & \\
\hline & Previous head trauma & $90(100)^{\mathrm{a}}$ & & & & \\
\hline & Yes & $23(25)$ & NA & $15.70(5.12)$ & NA & 0.299 \\
\hline & No & $67(75)$ & & $14.39(5.21)$ & & \\
\hline
\end{tabular}


Table 1 Socio-demographic, injury-related, clinical, and claim-related characteristics of the study population (Continued)

\begin{tabular}{|c|c|c|c|c|c|c|}
\hline & $\begin{array}{l}\text { Trauma-related head MRI } \\
\text { findings }\end{array}$ & $84(100)^{\mathrm{a}}$ & & & & \\
\hline & Yes & 0 & NA & NA & NA & NA \\
\hline & No & $84(100)$ & & & & \\
\hline \multirow[t]{38}{*}{ Clinical } & \multicolumn{6}{|l|}{$\begin{array}{l}\text { Comorbid conditions by } \\
\text { self-report }\end{array}$} \\
\hline & Arthritis & $93(100)^{a}$ & & & & \\
\hline & Yes & $34(37)$ & NA & $15.05(5.24)$ & NA & 0.868 \\
\hline & No & $59(63)$ & & $13.59(5.09)$ & & \\
\hline & \multicolumn{6}{|l|}{ Diabetes mellitus } \\
\hline & Yes & $5(5)$ & & $10.40(3.78)$ & & 0.065 \\
\hline & No & $89(95)$ & & $14.81(5.20)$ & & \\
\hline & \multicolumn{6}{|l|}{ Heart disease } \\
\hline & Yes & $6(6)$ & & $13.17(8.13)$ & & 0.057 \\
\hline & No & $88(94)$ & & $14.67(5.01)$ & & \\
\hline & $\begin{array}{l}\text { Number of comorbid } \\
\text { conditions }\end{array}$ & $94(100)$ & $2.22(1.04)$ & NA & -0.216 & 0.037 \\
\hline & \multicolumn{6}{|l|}{ DSM-IV-TR disorders } \\
\hline & Adjustment disorder & $88(100)^{a}$ & & & & \\
\hline & Yes & $45(51)$ & NA & $13.80(5.62)$ & NA & 0.265 \\
\hline & No & $43(49)$ & & $15.05(4.75)$ & & \\
\hline & \multicolumn{6}{|l|}{ Anxiety disorder } \\
\hline & Yes & $40(45)$ & & $13.08(5.49)$ & & 0.028 \\
\hline & No & $48(55)$ & & $15.52(4.76)$ & & \\
\hline & \multicolumn{6}{|l|}{ Mood disorder } \\
\hline & Yes & $37(42)$ & & $13.92(6.14)$ & & 0.456 \\
\hline & No & $51(58)$ & & $14.75(4.57)$ & & \\
\hline & Personality traits & $92(100)^{a}$ & & & & \\
\hline & \multicolumn{6}{|l|}{ Cluster B } \\
\hline & Yes & $15(17)$ & & $9.87(3.16)$ & & $<0.0001$ \\
\hline & No & $77(83)$ & & $15.50(5.11)$ & & \\
\hline & \multicolumn{6}{|l|}{ Cluster C } \\
\hline & Yes & $42(47)$ & & $13.50(5.66)$ & & 0.034 \\
\hline & No & $50(53)$ & & $15.88(4.47)$ & & \\
\hline & \multicolumn{6}{|l|}{ Sleep disorder } \\
\hline & Yes & $9(10)$ & & $17.71(4.27)$ & & 0.977 \\
\hline & No & $79(90)$ & & $17.79(6.23)$ & & \\
\hline & \multicolumn{6}{|l|}{$\begin{array}{l}\text { Substance-related } \\
\text { disorder }\end{array}$} \\
\hline & Yes & $13(15)$ & & $12.69(5.07)$ & & 0.200 \\
\hline & No & $75(85)$ & & $14.71(5.22)$ & & \\
\hline & \multicolumn{6}{|l|}{$\begin{array}{l}\text { Comorbid conditions, by } \\
\text { scales }\end{array}$} \\
\hline & Anxiety (HADS-A) & NA & $10.71(4.74)$ & NA & -0.317 & 0.002 \\
\hline & Depression (PHQ-9) & & $16.77(6.67)$ & & -0.320 & 0.002 \\
\hline & Insomnia (ISI) & & $17.46(6.07)$ & & -0.370 & $<0.001$ \\
\hline
\end{tabular}


Table 1 Socio-demographic, injury-related, clinical, and claim-related characteristics of the study population (Continued)

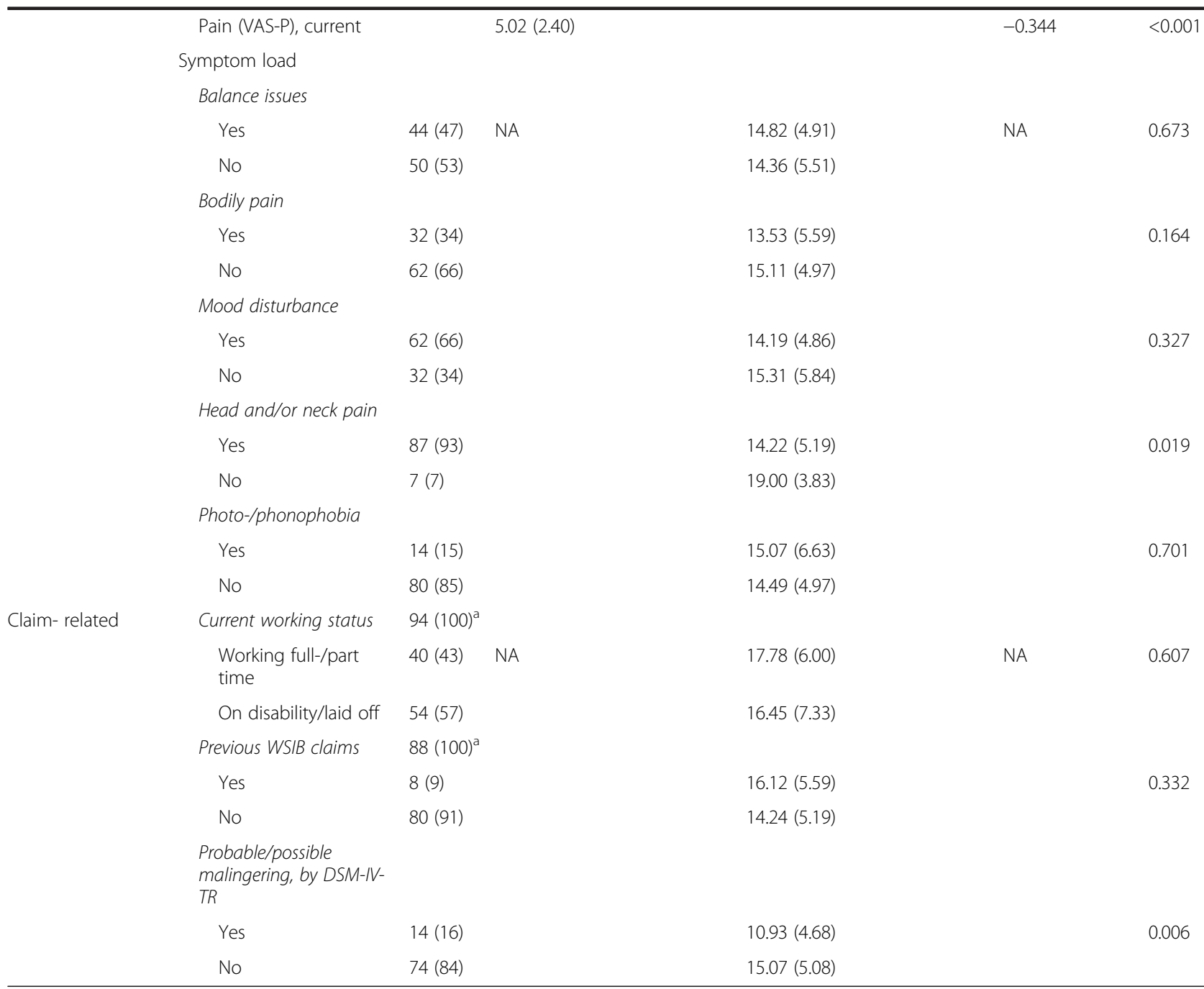

${ }^{\mathrm{a}} \mathrm{N}=94$ unless otherwise specified

${ }^{\mathrm{b} C o m m u n i t y ~ i n t e g r a t i o n ~ s c o r e s ~ w e r e ~ c o m p a r e d ~ u s i n g ~ a n a l y s i s ~ o f ~ v a r i a n c e ~ o r ~ S p e a r m a n ' s ~ c o r r e l a t i o n ~ t e s t s ~}$

NA Not applicable

inanimate objects, insomnia, head and/or neck pain, and Axis IV-TR malingering as independent variables. After the stepwise selection, the final model explained $36.6 \%$ of the $\mathrm{CI}$ variance, and contained five significant variables: insomnia $(\beta=-0.250, p<0.001)$, Axis IV-TR malingering $(\beta=-4.923, p<0.001)$, TSI $(\beta=-0.002, p=0.025)$, head and/or neck pain $(\beta=-4.186, p=0.015)$, and marital status $(\beta=-2.087, p=0.048)$ (Table 2 and Fig. 5).

\section{Discussion}

In this study of 94 workers with mTBI, we found that insomnia, head or neck pain, being married or in a relationship, TSI, and a diagnosis of possible/probable malingering were independently associated with limited CI.

Unfortunately, there are no normative data for CIQ scores in mTBI. However, the CIQ total and subscale scores in the present study were similar to the mean scores at 1 year post-injury in participants with more severe TBI, as reported by Sanders et al. (GCS: $8.43 \pm 3.8$ ) [40] and Seale et al. (GCS: $6.5 \pm 3.7$ ) [41]. As in previous studies $[42,43]$, the highest scores were observed in the social integration domain and the lowest scores were observed in the productive activities domain. However, our participants had slightly higher scores in the home integration domain. One possible explanation for this discrepancy is that our study evaluated workers with persistent symptoms, and the majority of participants were receiving disability benefits at their time of assessment. Thus, our data suggests that disability status is strongly associated with impaired productive activity, although it had a lesser effect on social and family integration in our study.

Our findings also highlight the associations between insomnia, pain, and depression, in agreement with earlier 


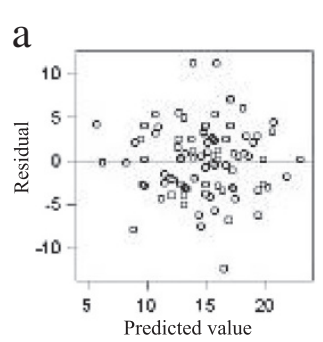

d
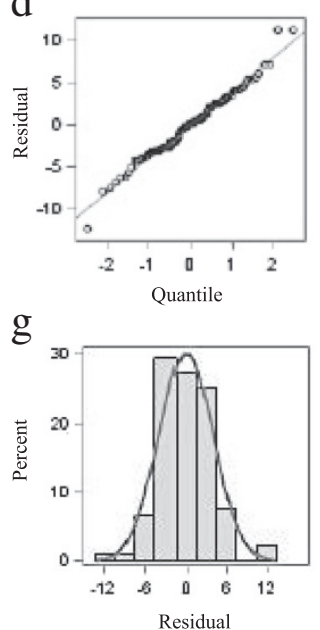

b

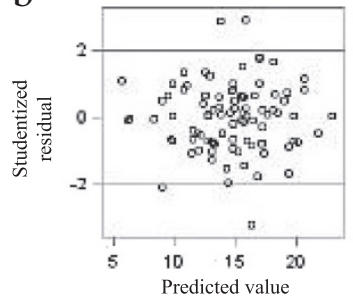

e

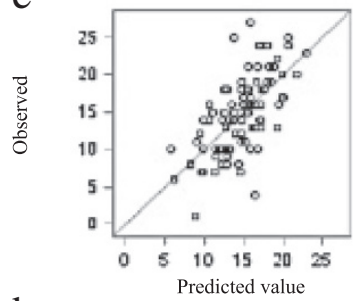

$\mathrm{h}$

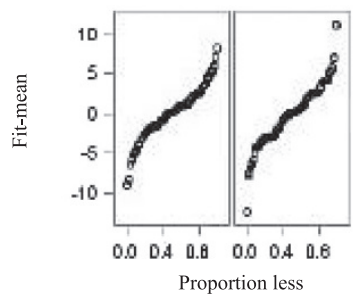

c

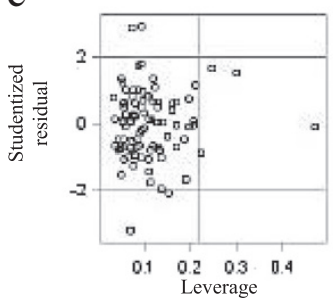

f
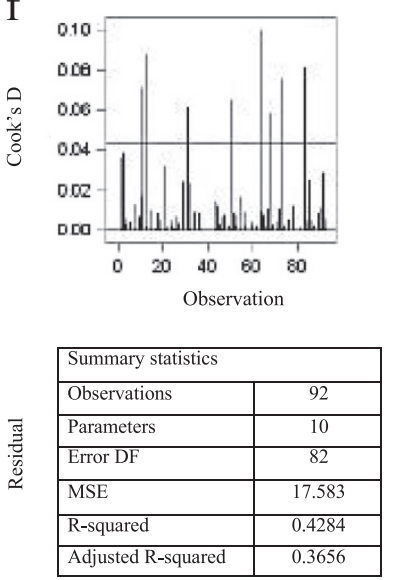

Fig. 3 Fit diagnostics for community integration (a-h)

reports [42-49]. However, insomnia has been viewed as a symptom that occurs in the context of another disorder (i.e., depression [42-45], pain [46-48], or brain injury [49]), rather than as an independent disorder within mTBI. In many depressed individuals, however, insomnia signals the onset of depression and may prevent recovery, even after adequate treatment $[50,51]$. Similarly, the stress created by insomnia may aggravate or serve as a catalyst for the involvement of the hypothalamic orexinergic or hypocretinergic system in pain and headaches [52]. This may be relevant for our participants, as the majority continued to experience pain and depressive symptoms, despite being diagnosed with and treated for both at their assessment. Therefore, insomnia and its causes should be addressed separately from depression and pain in mTBI, in order to maximize treatment outcomes, especially regarding $\mathrm{CI}$.

We also found that a diagnosis of possible/probable malingering was associated with a poorer CI. Although the presence of malingering or symptom exaggeration does not preclude the existence of symptoms or disorders, it does make the quantification of these issues impossible [53, 54]. Therefore, future research should be designed identify the determinants of a malingering diagnosis among injured workers. According to the DSM-IV, a diagnosis of malingering is appropriate when $\geq 2$ of 4 criteria are met $[36,55]$ : (1) presentation of symptoms in a medico-legal context, (2) discordance between the individual's stated disability and objective data, (3) uncooperative behavior during evaluation, and (4) presentation of antisocial personality disorder. However, our participants met the first two criteria, as they were referred by the WSIB for evaluation and MTBI is a clinical diagnosis that cannot be confirmed with objective data (i.e., none of our participants had positive MRI findings, and there is currently no sensitive and specific imaging technique to diagnose $\mathrm{mTBI})[55,56]$. In addition, a worker with certain personality traits may find being questioned about their disability or injury to be unnerving, which may satisfy the third criterion independent of any malingering. Furthermore, recommendations have been published to implement neuropsychological testing for possible malingering in persons with TBI [57]. This raises the issue of language proficiency $[49,58]$, as these evaluations would be performed using tests that were developed in English and have not been validated in other languages. Therefore, English proficiency is an important variable to consider in future studies regarding performance validity.

We also found that a longer TSI was associated with a poorer CI after mTBI. Although this association was not evaluated longitudinally, our results may indicate that other relevant factors (e.g., psychological, medical, or 

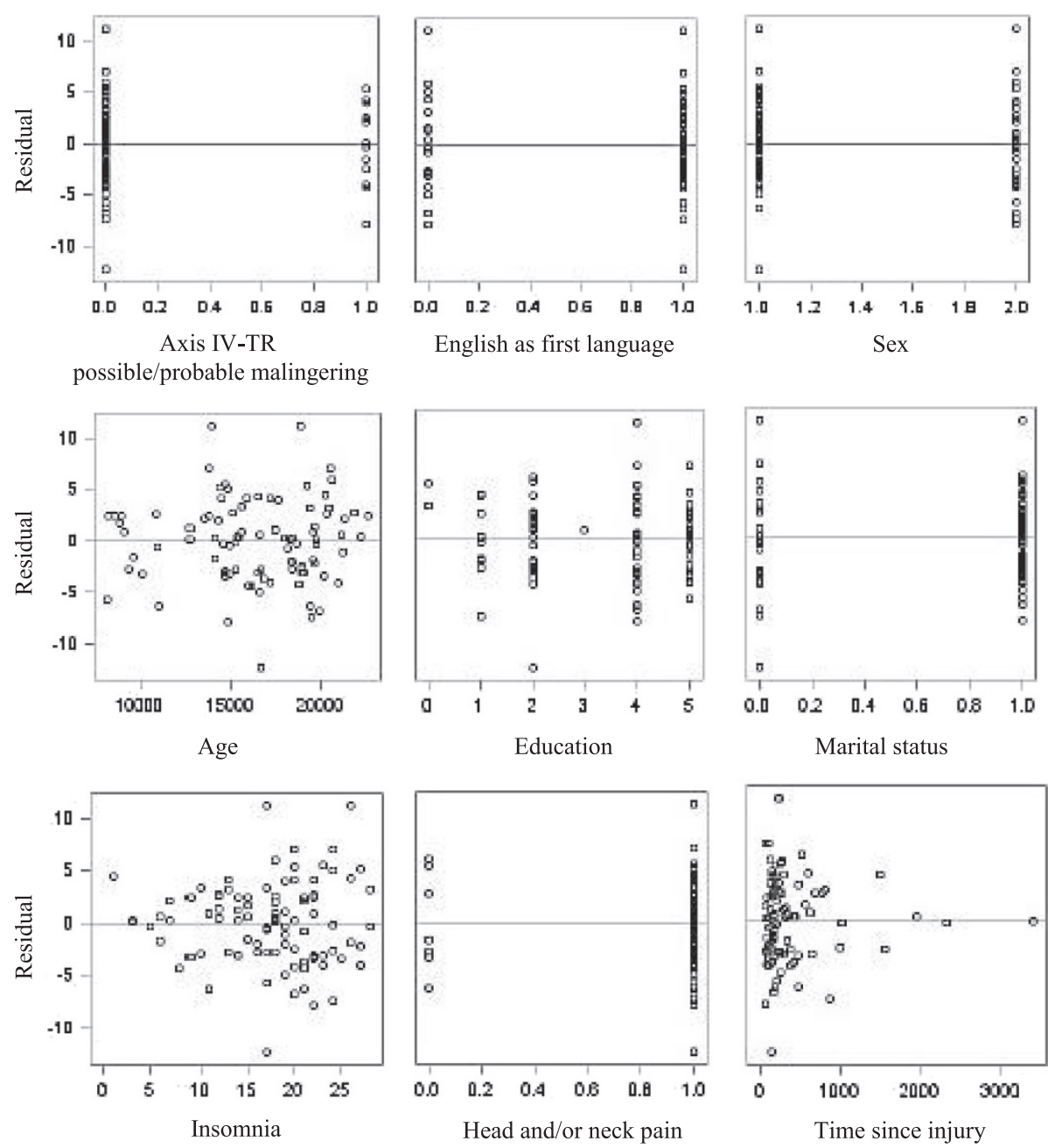

Fig. 4 Residuals by regressor for community integration

other) can develop after the mTBI and strengthen over time, thereby impeding CI [59]. Similarly, psychological and psychosocial factors that present in the early postinjury period can influence outcomes across the entire recovery timeline [60]. Unfortunately, the cross-sectional nature of our study does not allow us to provide insight regarding this topic. Nonetheless, our results support the notion that patient assessments should begin as early as possible, which can establish baseline findings for $\mathrm{CI}$ and time-dependent outcomes.

Unexpectedly, being married was not related to a better $\mathrm{CI}$, and our results indicate that marriage had a

Table 2 Summary of the stepwise multiple regression analysis for the final model, sex and age adjusted

\begin{tabular}{|c|c|c|c|c|c|c|}
\hline From model & Variable & $\beta$ Coefficient & SE & $P$ value & Partial $R^{2}$ & Model $\mathrm{R}^{2}$ \\
\hline \multirow[t]{3}{*}{ \#1 Socio-demographic } & Education & 0.380 & 0.323 & 0.242 & 0.011 & 0.011 \\
\hline & English as first language & 1.304 & 1.179 & 0.272 & 0.018 & 0.029 \\
\hline & Marital status & -2.087 & 1.041 & 0.048 & 0.043 & 0.072 \\
\hline \multirow[t]{2}{*}{ \#2 Clinical } & Insomnia & -0.250 & 0.076 & $<0.001$ & 0.159 & 0.231 \\
\hline & Head and/or neck pain & -4.186 & 1.679 & 0.015 & 0.039 & 0.270 \\
\hline \#3 Claim-related & Axis-IV-TR malingering & -4.923 & 1.302 & $<0.001$ & 0.069 & 0.339 \\
\hline \multirow[t]{2}{*}{ \#4 Injury- related } & Time since injury & -0.002 & 0.001 & 0.025 & 0.075 & 0.414 \\
\hline & Struck by inanimate object & 1.965 & 1.059 & 0.076 & 0.014 & 0.428 \\
\hline
\end{tabular}




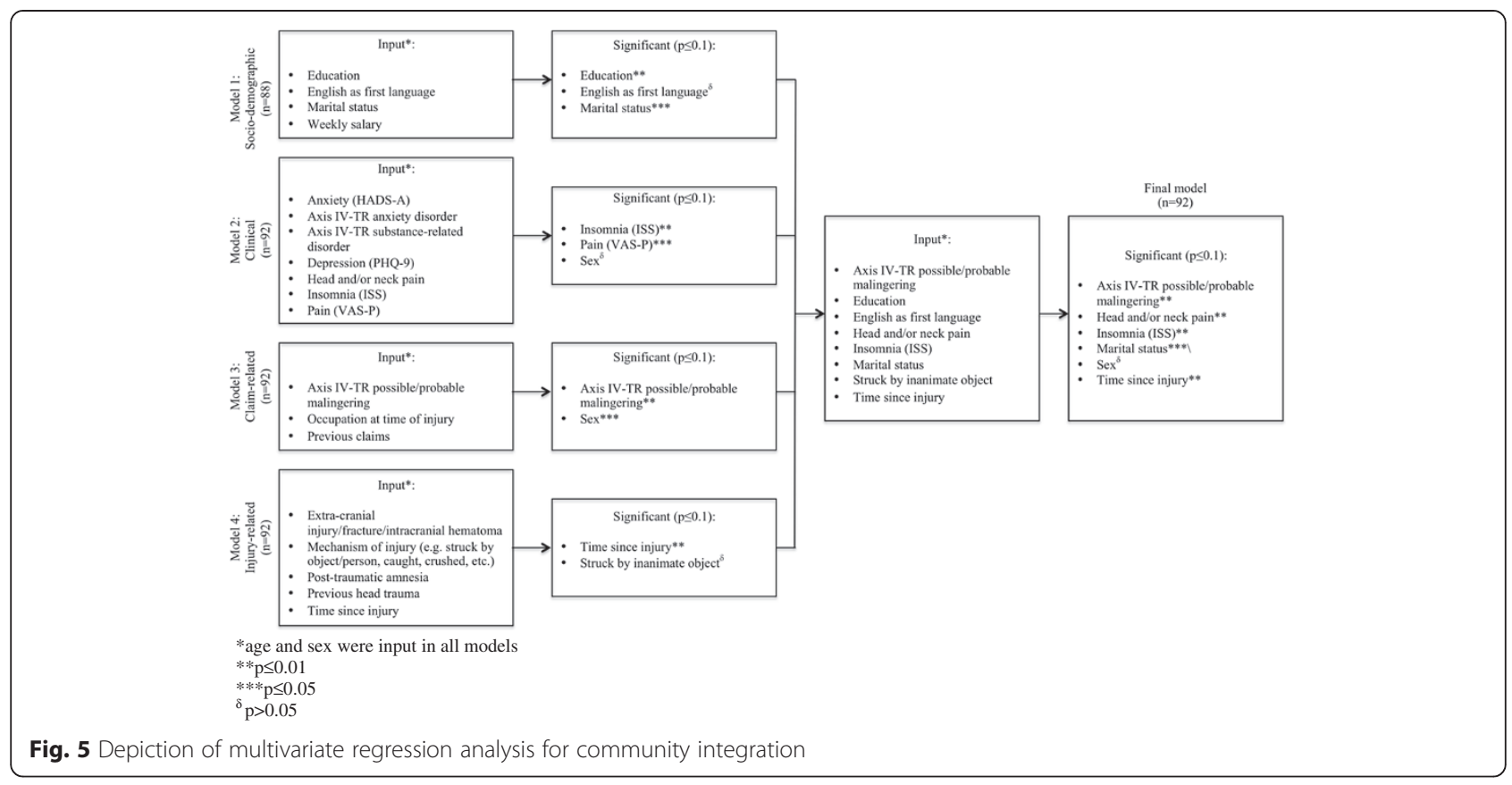

negative effect on CI. In contrast, earlier studies have reported that married people with a disability have higher levels of life satisfaction [61, 62], fewer handicaps [63], and longer life expectancy [64], compared to their unattached counterparts. However, our results should be interpreted with caution, as one-third of our participants were single, divorced, or widowed at the time of assessment, and we did not assess whether or not this status changed after their injury. Nevertheless, our findings suggest that workers who are married or in relationships may rely on their partners for assistance in performing their family and societal duties, which would hinder their independent CI. This observation highlights uncertainty regarding the role of marriage and/or partner support in the context of compromised CI, and longitudinal analysis of relationship status and patient outcomes (both personal and familial) may provide insight regarding their interdependence and independence.

The strengths of our study include a well-characterized sample of insured workers with a confirmed mTBI diagnosis. In addition, this is the first study to simultaneously address the prevalence of various sociodemographic, clinical, claim-related, and TBI-related variables, and their subsequent impact on CI. Furthermore, we utilized the TRIPOD checklist, which is a valuable reference for good reporting of multivariable prediction models. Therefore, the present study provides foundational data for a comprehensive longitudinal study that can evaluate the risk factors for prolonged recovery and reduced post-mTBI CI.

Our study has several limitations. First, our model for estimating CI was complex, which reflects the large number of covariates that were associated with $\mathrm{CI}$ and were not included in our final model. Therefore, a study with a large sample, standardized data collection and calculations will be needed to validate our model. Second, generalization of our findings may be limited, as a high prevalence of clinically relevant disorders was observed in our sample, and each of these disorders have been associated with poor post-injury outcomes. Furthermore, our study only aimed to evaluate workers who had a prolonged recovery after their injury, as they experience the greatest effects of mTBI and are the most difficult to rehabilitate. Third, the $\mathrm{R}^{2}$ value of 0.366 for our final regression analysis indicates that that only 36 . $6 \%$ of the variance in the mean CI can be explained by the above named variables and insomnia explains most of the variance (i.e., $15.9 \%$ ). This finding may be due to the omission of information regarding various critical CI areas, such as psychological sense of community, satisfaction with community, and perception of safety [65-67]. However, given that our results support the notion of CI as a time-dependent construct, and our data consisted of various time series, the $\mathrm{R} 2$ value for insomnia provides solid support of it as a covariate of $\mathrm{CI}$, bearing in mind the fact that we are looking for meaningful associations in the context of delayed recovery from mTBI in the presence of many a priori defined relationships and a relatively small sample size.

Finally, this study highlighted the factors that were associated with $\mathrm{CI}$ in a population of workers with $\mathrm{mTBI}$, although the longitudinal relationships between these factors and poor post-injury outcomes remain to be 
determined. Therefore, further research regarding this topic may facilitate the development of interventions that improve the $\mathrm{CI}$ of injured workers with mTBI.

\section{Conclusions}

Community integration is increasingly being recognized as a highly relevant outcome in outpatient populations, and is currently listed among the criteria that are used to assess the participation domain of the International Classification of Functioning, Disability, and Health [68] after TBI. Our results suggest that the CI may differ across various clinical populations, based on the presence or absence of insomnia and head or neck pain. Therefore, specialists who assess workers with mTBI should be particularly sensitive to these complaints, and should thoroughly investigate the etiology of these symptoms. In addition, we found that marital status may hinder $\mathrm{CI}$, and that CI was related to an Axis IV-TR diagnosis of malingering. Thus, efforts to increase post-injury CI should be guided by a comprehensive understanding of the diverse factors that contribute to outcomes beyond the persistent post-concussive symptoms.

\section{Additional files}

Additional file 1: Table S1. Standardized measured used, with examples of uses in TBI populations and their evaluated applicability [69-72]. (DOCX $45 \mathrm{~kb})$

Additional file 2: Table S2. Categories and types of variables collected. (DOCX $16 \mathrm{~kb}$ )

\section{Abbreviations \\ CIQ: Community integration questionnaire; GCS: Glasgow coma scale; HADS-A: Hospital anxiety and depression scale; LOC: Loss of consciousness; MRI: Magnetic resonance imaging; mTBI: Mild traumatic brain injury; MVI: Motor vehicle injury; PHQ-9: Patient health questionnaire-9; PTA: Post-traumatic amnesia; P-VAS: Pain visual analogue scale; RTW: Return to work; SD: Standard deviation; TSI: Time since injury; TBI: Traumatic brain injury; TRIPOD: Transparent reporting of a multivariable prediction model for individual prognosis or diagnosis; UHN: University health network; WSID: Workplace safety and insurance board.}

\section{Competing interests}

The authors declare that they have no competing interest.

\section{Authors' contributions}

TM: developed study concept and design, was responsible for acquisition of data, statistical analysis (with the help of LV, acknowledged), interpretation of data and drafting of the manuscript. CMS: participated in the design of the study, interpretation of data and general supervision of the first author. SM: provided administrative, technical, proofreading, and material support. DJC: participated in the design of the study, interpretation of data and general supervision of the first author. AC: supervised TM in the development of the study design, statistical analysis and interpretation of data. All authors provided critical revision of the manuscript for important intellectual content and approved the final manuscript.

Authors' information

Not applicable.
Availability of data and materials

Not applicable.

\section{Acknowledgements}

We gratefully acknowledge Mr. Kevin McCurley for his help with the data management, Mr. Chen Xiong for his help with the re-abstraction of the data, Ms. Lee Vernich (Dalla Lana School of Public Health) for her help with the statistical analysis. The first author was supported by 2012/2013 Toronto Rehabilitation Institute Scholarship, the Ontario Graduate Scholarship 2012/2013 and the 2013/2015 Frederick Banting and Charles Best Doctoral Research Award from the Canadian Institutes of Health Research (CIHR) and the Work Disability Prevention CIHR Strategic Training Program. AC was supported by the CIHR Chair in Gender, Work and Health (CGW-126580). The funders had no role in study design, data collection and analysis, decision to publish, or preparation of the manuscript.

\section{Author details}

${ }^{1}$ Graduate Department of Rehabilitation Science, Collaborative Program in Neuroscience, University of Toronto, Toronto, Canada. ${ }^{2}$ Toronto Rehab-University Health Network, Ontario, Canada. ${ }^{3}$ Toronto Western Hospital, University Health Network, Ontario, Canada. ${ }^{4}$ Youthdale Child \& Adolescent Sleep Clinic, Ontario, Canada. ${ }^{5}$ Faculty of Arts and Science, University of Toronto, Toronto, Canada. ${ }^{6}$ Aquired Brain Injury Research Lab, University of Toronto, Toronto, Canada. ${ }^{7}$ Division of Epidemiology, Dalla Lana School of Public Health, University of Toronto, Toronto, Canada. ${ }^{8}$ Department of Sport Science and Clinical Biomechanics, Faculty of Health, University of Southern Denmark, Odense, Denmark. ${ }^{9}$ Department of Occupational Science and Occupational Therapy, University of Toronto Ontario, Ontario, Canada.

Received: 25 April 2015 Accepted: 16 September 2015

Published online: 09 October 2015

\section{References}

1. World Health Organization. Traumatic brain injury: neurological disorders. Public health challenges. Geneva: WHO Press; 2006.

2. Hyder A, Wunderlich C, Puvanachandra P, Gururaj G, Kobusingye O. The impact of traumatic brain injuries: a global perspective. NeuroRehabilitation. 2007;22:341-53.

3. World Health Organization. Projection of Mortality and Burden of Disease to 2030. Death by Income Group. Geneva: WHO Press; 2002.

4. Liao CC, Chou YC, Yeh CC, Hu CJ, Chiu WT, Chen TL. Stroke risk and outcomes in patients with traumatic brain injury: 2 nationwide studies. Mayo Clin Proc. 2014;89:163-72.

5. Catroppa C, Crossley L, Hearps SJ, Yeates KO, Beauchamp M, Rogers K, et al. Social and behavioral outcomes: pre-injury to 6 months following childhood traumatic brain injury.

J Neurotrauma. 2015;32:109-15.

6. Corrigan JD, Cuthbert JP, Harrison-Felix C, Whiteneck GG, Bell JM, Miller AC, et al. US population estimates of health and social outcomes 5 years after rehabilitation for traumatic brain injury. J Head Trauma Rehabil. 2014;29:E1-9.

7. Lewis FD, Horn GJ. Traumatic brain injury: analysis of functional deficits and posthospital rehabilitation outcomes. J Spec Oper Med. 2013;13:56-61.

8. Hart T, Sherer M, Temkin N, Whyte J, Dikmen S, Heinemann AW, et al. Participant-proxy agreement on objective and subjective aspects of societal participation following traumatic brain injury. J Head Trauma Rehabil. 2010;25:339-48.

9. Williams MW, Rapport LJ, Millis SR, Hanks RA. Psychosocial outcomes after traumatic brain injury: life satisfaction, community integration, and distress. Rehabil Psychol. 2011;59:298-305.

10. Turgeon AF, Lauzier F, Simard JF, Scales DC, Burns KE, Moore L, et al. Mortality associated with withdrawal of life-sustaining therapy for patients with severe traumatic brain injury: a Canadian multicentre cohort study. CMAJ. 2011;183:1581-8.

11. Grauwmeijer E, Heijenbrok-Kal MH, Ribbers GM. Health-related quality of life 3 years after moderate to severe traumatic brain injury: a prospective cohort study. Arch Phys Med Rehabil. 2014;95:1268-76.

12. Forslund MV, Roe C, Sigurdardottir S, Andelic N. Predicting health-related quality of life 2 years after moderate-to-severe traumatic brain injury. Acta Neurol Scand. 2013;128:220-7. 
13. Wertheimer JC, Hanks RA, Hasenau DL. Comparing functional status and community integration in severe penetrating and motor vehicle-related brain injuries. Arch Phys Med Rehabil. 2008;89:1983-90.

14. Sugerman DE, Xu L, Pearson WS, Faul M. Patients with severe traumatic brain injury transferred to a Level I or II trauma center: United States, 2007 to 2009. J Trauma Acute Care Surg. 2012;73:1491-9.

15. Zelnick LR, Morrison LJ, Devlin SM, Bulger EM, Brasel KJ, Sheehan K, et al. Addressing the challenges of obtaining functional outcomes in traumatic brain injury research: missing data patterns, timing of follow-up, and three prognostic models. Resuscitation Outcomes Consortium Investigators. J Neurotrauma. 2014;31:1029-38.

16. National Center for Injury Prevention and Control, Centers for Disease Control and Prevention (CDC). Report to Congress on Mild Traumatic Brain Injury in the United States: Steps to Prevent a Serious Public Health Problem. [Atlanta: Centers for Disease Control and Prevention; 2003.

17. Mild Traumatic Brain Injury Committee, A. C. o. R. M, Head Injury Interdisciplinary Special Interest Group. Definition of mild traumatic brain injury. J Head Trauma Rehabil. 1993;8:86-7.

18. Hou R, Moss-Morris R, Peveler R, Mogg K, Bradley BP, Belli A. When a minor head injury results in enduring symptoms: a prospective investigation of risk factors for postconcussional syndrome after mild traumatic brain injury. J Neurol Neurosurg Psychiatry. 2012;83:217-23.

19. Merrick D, Stålnacke BM. Five years post whiplash injury: symptoms and psychological factors in recovered versus non-recovered. BMC Res Notes. 2010;3:190.

20. Maroon JC, Mathyssek C, Bost J. Cerebral concussion: a historical perspective. Prog Neurol Surg. 2014;28:1-13.

21. Kraus JF, Hsu P, Schafer K, Afifi AA. Sustained outcomes following mild traumatic brain injury: results of a five-emergency department longitudinal study. Brain Inj. 2014;28:1248-56.

22. Carroll $\sqcup$, Cassidy JD, Peloso PM, Garritty C, Giles-Smith L, et al. WHO Collaborating Centre Task Force on Mild Traumatic Brain Injury. Prognosis for mild traumatic brain injury: results of the WHO Collaborating Centre Task Force on Mild Traumatic Brain Injury. J Rehabil Med. 2004;43(Suppl):84-105.

23. Buysse DJ. Insomnia. JAMA. 2013;309:706-16.

24. Paunio T, Korhonen T, Hublin C, Partinen M, Koskenvuo K, Koskenvuo M, et al. Poor sleep predicts symptoms of depression and disability retirement due to depression. J Affect Disord. 2014;172C:381-9.

25. Sivertsen B, Lallukka T, Salo P, Pallesen S, Hysing M, Krokstad S, et al. Insomnia as a risk factor for ill health: results from the large populationbased prospective HUNT Study in Norway. J Sleep Res. 2014;23(2):124-32.

26. Perel P, Edwards P, Wentz R, Roberts I. Systematic review of prognostic models in traumatic brain injury. BMC Med Inform Decis Mak. 2006;6:38.

27. Lingsma HF, Yue JK, Maas Al, Steyerberg EW, Manley GT, TRACK-TBI Investigators, et al. Outcome prediction after mild and complicated mild traumatic brain injury: external validation of existing models and identification of new predictors using the track-TBI pilot study. J Neurotrauma. 2015;32:83-94.

28. Jacobs B, Beems T, Stulemeijer M, van Vugt AB, van der Vliet TM, Borm GF, et al. Outcome prediction in mild traumatic brain injury: age and clinical variables are stronger predictors than $\mathrm{CT}$ abnormalities. J Neurotrauma. 2010;27:655-68

29. MRC CRASH Trial Collaborators, Perel P, Arango M, Clayton T, Edwards P, Komolafe E, et al. Predicting outcome after traumatic brain injury: practical prognostic models based on large cohort of international patients. BMJ. 2008:336:425-9.

30. Stulemeijer M, van der Werf S, Borm GF, Vos PE. Early prediction of favourable recovery 6 months after mild traumatic brain injury. J Neurol Neurosurg Psychiatry. 2008;79:936-42.

31. Quatrano LA, Cruz TH. Future of outcome measurement: impact on research in medical rehabilitation and neurologic populations. Arch Phys Med Rehabil. 2011;92 Suppl 10:S7-11.

32. Parker G, Bernard S, Gridley K, Aspinal F, Light K. Rapid systematic review of international evidence on integrated models of care for people with long-term neurological conditions: technical report. SPRU Working Paper No SDO 2400. York: Social Policy Research Unit, University of York; 2010.

33. von Bonsdorff MB, Seitsamo J, Ilmarinen J, Nygård CH, von Bonsdorff ME, Rantanen T. Work ability in midlife as a predictor of mortality and disability in later life: a 28-year prospective follow-up study. CMAJ. 2011;183(4):E235-42.
34. Willer B, Rosental M, Kreutzer JS, Gordon WA, Rempel R. Assessment of community integration following rehabilitation for traumatic brain injury. J Head Trauma Rehabil. 1993;8:75-87.

35. Collins GS, Reitsma JB, Altman DG, Moons KG. Transparent Reporting of a Multivariable Prediction Model for Individual Prognosis Or Diagnosis (TRIPOD): the TRIPOD statement. J Clin Epidemiol. 2015;68:134-43.

36. American Psychiatric Association. Diagnostic and statistical manual of mental disorder. 4th ed. Washington: American Psychiatric Association; 2000.

37. Lequerica AH, Chiaravalloti ND, Sander AM, Pappadis MR, Arango-Lasprilla JC, Hart T, et al. The Community Integration Questionnaire: factor structure across racial/ethnic groups in persons with traumatic brain injury. J Head Trauma Rehabil. 2013;28:E14-22.

38. Norman GR, Streiner DL. Biostatistics: the bare essentials. Hamilton: B.C. Decker; 2000.

39. Dupont DW. Statistical modelling for biomedical researchers. A simple introduction to the analysis of complex data. 2nd ed. New York: Cambridge University Press; 2009.

40. Sander AM, Fuchs KL, High WM, Hall KM, Kreutzer JS, Rosental M. The Community Integration Questionnaire revisited: an assessment of factor structure and validity. Arch Phys Med Rehabil. 1999;80:1303-8.

41. Seale GS, Caroselli JS, High Jr WM, Becker CL, Neese LE, Scheibel R. Use of the Community Integration Questionnaire $(\mathrm{ClQ})$ to characterize changes in functioning for individuals with traumatic brain injury who participated in a post-acute rehabilitation programme. Brain Inj. 2002;16:955-67.

42. Holbrook AM, Crowther R, Lotter A, Cheng C, King D. The diagnosis and management of insomnia in clinical practice: a practical evidence-based approach. CMAJ. 2000;162(2):216-20.

43. Sutton EL. Psychiatric disorders and sleep issues. Med Clin North Am. 2014;98:1123-43.

44. Mason EC, Harvey AG. Insomnia before and after treatment for anxiety and depression. J Affect Disord. 2014;168:415-21.

45. Soehner AM, Kaplan KA, Harvey AG. Prevalence and clinical correlates of co-occurring insomnia and hypersomnia symptoms in depression. J Affect Disord. 2014;167:93-7.

46. Chung S, Bohnen NI, Albin RL, Frey KA, Müller ML, Chervin RD. Insomnia and sleepiness in Parkinson disease: associations with symptoms and comorbidities. J Clin Sleep Med. 2013;9:1131-7.

47. Alföldi P, Wiklund T, Gerdle B. Comorbid insomnia in patients with chronic pain: a study based on the Swedish quality registry for pain rehabilitation (SQRP). Disabil Rehabil. 2014;36:1661-9.

48. Emery PC, Wilson KG, Kowal J. Major depressive disorder and sleep disturbance in patients with chronic pain. Pain Res Manag. 2014;19:35-41.

49. Ouellet MC, Savard J, Morin CM. Insomnia following traumatic brain injury: a review. Neurorehabil Neural Repair. 2004;18:187-98.

50. Baglioni C, Battagliese G, Feige B, Spiegelhalder K, Nissen C, Voderholzer U, et al. Insomnia as a predictor of depression: a meta-analytic evaluation of longitudinal epidemiological studies. J Affect Disord. 2011;135:10-9.

51. Macera CA, Aralis HJ, Rauh MJ, MacGregor AJ. Do sleep problems mediate the relationship between traumatic brain injury and development of mental health symptoms after deployment? Sleep. 2013;36:83-90.

52. Holland P, Goadsby PJ. The hypothalamic orexinergic system: pain and primary headaches. Headache. 2007;47(6):951-62.

53. Belanger $H$, Barwick F, Kip K, Kretzmer T, Vanderploeg R. Postconcussive symptom complaints and potentially malleable positive predictors. Clin Neuropsychol. 2013;27:343-55.

54. LoPiccolo CJ, Goodkin K, Baldewicz TT. Current issues in the diagnosis and management of malingering. Ann Med. 1999:31:166-74.

55. Fox WC, Park MS, Belverud S, Klugh A, Rivet D, Tomlin JM. Contemporary imaging of mild TBI: the journey toward diffusion tensor imaging to assess neuronal damage. Neurol Res. 2013;35:223-32.

56. Schrader H, Mickeviciene D, Gleizniene R, Jakstiene S, Surkiene D, Stovner L, et al. Magnetic resonance imaging after most common form of concussion. BMC Med Imaging. 2009;9:11.

57. Bordini EJ, Chaknis MM, Ekman-Turner RM, Perna RB. Advances and issues in the diagnostic differential of malingering versus brain injury. NeuroRehabilitation. 2002;17:93-104.

58. Rosselli M, Ardila A, Santisi MN, Arecco Mdel R, Salvatierra J, Conde A, et al. Stroop effect in Spanish-English bilinguals. J Int Neuropsychol Soc. 2002;8:819-27.

59. Lishman W. Physiogenesis and psychogenesis in the post concussional syndrome. Br J Psychiatry. 1988;153:460-9. 
60. Silverberg $\mathrm{N}$, Iverson $\mathrm{G}$. Etiology of the post-concussion syndrome: physiogenesis and psychogenesis revisited. NeuroRehabilitation. 2011;29:317-29.

61. Ross CE. Reconceptualizing marital status as a continuum of social attachment. J Marriage Fam. 1995;57:129-40.

62. Soons JPM, Liefbroer AC, Kalmijn M. The long-term consequences of relationship formation for subjective well-being. J Marriage Fam. 2009; $71: 1254-70$

63. Kreuter M, Sullivan M, Dahllof A, Siosteen A. Partner relationships, functioning, mood and global quality of life in persons with spinal cord injury and traumatic brain injury. Spinal Cord. 1998;36:252-61.

64. Chang FH, Wang YH, Jang Y, Wang CW. Factors associated with quality of life among people with spinal cord injury: application of the International Classification of Functioning, Disability and Health model. Arch Phys Med Rehabil. 2012;93:2264-70.

65. Rogers S, Howard G. Patient and community engagement: the approach at university health network. Healthc Q. 2014;17:70-3.

66. Kirmayer LJ, Narasiah L, Munoz M, Rashid M, Ryder AG, Guzder J, et al. Common mental health problems in immigrants and refugees: general approach in primary care. CMAJ. 2011;183(12):E959-67.

67. McMillan DW, Chavis DM. Sense of community: a definition and theory. J Community Psychol. 1986;14:6-23.

68. World Health Organization. Towards a common language for functioning, disability and health: ICF. 2002. Available: http://www.who.int/classifications/icf/training/icfbeginnersguide.pdf (accessed 2014 Nov.30)

69. Fann JR, Bombardier CH, Dikmen S, Esselman P, Warms CA, Pelzer E, et al. Validity of the Patient Health Questionnaire-9 in assessing depression following traumatic brain injury. J Head Trauma Rehabil. 2005;20:501-11.

70. Dahm J, Wong D, Ponsford J. Validity of the Depression Anxiety Stress Scales in assessing depression and anxiety following traumatic brain injury. J Affect Disord. 2013;151:392-6.

71. Gagnon C, Bélanger L, Ivers H, Morin CM. Validation of the Insomnia Severity Index in primary care. J Am Board Fam Med. 2013;26:701-10.

72. Abrishami A, Khajehdehi A, Chung F. A systematic review of screening questionnaires for obstructive sleep apnea. Can J Anaesth. 2010:57:423-38.

73. Fayers PM, Hand DJ. Factor analysis, causal indicators, and quality of life. Qual Life Res 1997; 6: 139-50.

\section{Submit your next manuscript to BioMed Central and take full advantage of:}

- Convenient online submission

- Thorough peer review

- No space constraints or color figure charges

- Immediate publication on acceptance

- Inclusion in PubMed, CAS, Scopus and Google Scholar

- Research which is freely available for redistribution 